\title{
A parametric study of implementing green roofs to improve building energy performance in tropical climate
}

\author{
Agnieszka Moreno ${ }^{1}$, Miguel Chen Austin ${ }^{1,2}$ and Dafni Mora ${ }^{1,2, *}$ \\ ${ }^{1}$ Faculty of Mechanical Engineering, Universidad Tecnológica de Panamá, Panama City, Panama \\ ${ }^{2}$ Centro de Estudios Multidisciplinarios de Ingeniería, Ciencia y Tecnología (CEMCIT-AIP), Panama \\ City, Panama
}

\begin{abstract}
Energy is one of the most involving issues, its use, the way to spread it, and how to reduce its consumption. Because of this, it is important to opt for solutions that determine the final use of energy. The feasibility study of vegetation applied to green roofs for buildings would be a favorable solution to stop absorbing the heat that we consume daily, and at the same time, we produce. Thus, this research aims to evaluate the implementation of generic vegetation on the roof of buildings in Panama, in terms of electricity consumption for cooling, through dynamic simulation. For this, a parametric analysis was performed through the DesignBuilder program, where four plants suitable for the climate of Panama and resistant to solar radiation, high temperatures, and humidity were chosen, which were Tradescantia spathacea Sw., Sansevieria sp., Aloe Vera, and Arachis hypogaea. Employing passive and mechanical mode simulations with 24-hour irrigation systems, it was possible to observe how the temperature inside the building and the heat gains through the roof decrease. This led us to determine the most important parameters of the vegetation layer: plant height, leaf area index (LAI), leaf reflectivity, and stomatal resistance.
\end{abstract}

\section{Introduction}

The high concentration of buildings in cities has given rise to many environmental problems, such as the Urban Heat Island effect. The growing ecological concerns for building design attempt to create harmony between buildings and their surroundings through mitigating their negative impact on the environment. Greening buildings is essentially one of the green measures.

Energy is one of the most critical issues globally, its use, how to diffuse it, and how to mitigate its consumption. Therefore, it is important to look for solutions that determine the final use of energy. The feasibility study of vegetation applied to green roofs for buildings would be a favorable solution to stop absorbing the heat we consume daily and at the same time produce.

\footnotetext{
*Corresponding author: dafni.mora@utp.ac.pa
} 
Over time, the temperature has risen considerably, making the thermal sensation, for people, often unbearable. This is generated because every time people arrive at their offices or homes, they turn on the air conditioning and set it at a comfortable temperature, causing high energy consumption.

One of the main characteristics of green roofs is the type of plant that is planted on it. The climate is our main factor in determining which is the best option. In this case, the tropical climate is one of the biggest challenges as any plant does not support the heat. Singapore is a garden city with an increasing population and limited territory; the government adopted a high-density, high-rise residential strategy.

Modern green roofs are made of layers placed on the roof to support the soil medium and vegetation. Green roofs are also becoming increasingly popular in the United States, although they are not as common as in Europe [1].

The idea of implementing roof gardens and providing aesthetic value comes from countless studies that have shown that they provide temperature control for the building and, in many countries, have served as a habitat for wildlife. Also, in climates where the cold is the main actor, these covers have served as insulation against it and prevent flooding in times of constant rain.

As the population density in Port of Spain (Trinidad and Tobago) has increased over time, most of the population has concentrated in urban areas, which has led to flooding, new adaptations to climate change, rising energy costs, and other repercussions that have affected the comfort of how people live. This leads to a research thesis conducted in Trinidad and Tobago, a country with a tropical climate quite similar to Panama, where they date on all the characteristics of green roofs, its operation and its great results in Europe and how it could be implemented through policies, new national development strategies to increase urban sustainability. The results obtained in this research were very favorable regarding the heat mitigation of green roofs on buildings in urban areas and the important public benefits derived from using these systems on the rooftop [2].

Panama is currently suffering one of the biggest heat waves ever, both in the capital city and in the rest of the country. This is primarily due to climate change and in the capital city due to urban growth and construction. However, the implementation of green roofs in Panama can mitigate the impact of heat waves.

A green roof consists of the plant canopy layer, the growth medium (soil), a waterproof membrane, a protective membrane to protect the waterproofing from root penetration, a drainage layer usually made of gravel, a filter layer that separates the drainage layer.

The thickness of the growth medium dictates what type of plants the canopy layer can contain so that green roofs can be classified into intensive, semi-intensive, extensive, and semi-extensive [3]. Intensive green roofs have a soil thickness of at least $30 \mathrm{~cm}$ and can accommodate various plants, including small trees and shrubs. Due to the thick soil layer, intensive green roofs have a high water retention capacity, but they also have structural limitations. Green roofs with a soil thickness between $15-30 \mathrm{~cm}$ are called semi-intensive, can accommodate small plants and shrubs but still require high maintenance and require structural considerations on the building [4]. Extensive and semi-extensive green roofs have a 7-15 cm soil thickness and can only accommodate small plants such as grass or sedum. This type of green roof requires little maintenance, generally does not require irrigation, and is suitable for retrofitting older buildings because it is lightweight [5].

The thermal performance of green roofs can be improved by modulating the thickness of the soil; In this specific case study, it has been found that the thicker the soil layer, the better the thermal performance. However, the thermal performance of green roofs on non- 
insulated roofs differs from that of green roofs installed on well-insulated roofs. For example, Feng and Hewage found that installing an extensive green roof on a highly insulated five-story LEED1 building in Kelowna, Canada, had almost no influence on the building's energy demand in winter and summer. Similarly, Khabaz found that, in Saudi Arabia, while the extensive deployment of green roofs provides no thermal benefit over conventional roofs, intensive green roofs lower indoor air temperature.

In the hot climates of Phoenix, Los Angeles, Chicago, and Shanghai, it turned out that variation in green roof insulation and night ventilation provided by fans can optimize the summer thermal performance of green roofs.

Therefore, as no reported study exists, this research aims to evaluate the implementation of generic vegetation on the roof of buildings in Panama, in terms of electricity consumption for cooling, through dynamic simulation.

\section{Materials and methods}

To evaluate the implementation of green roof in Panama, in terms of thermal comfort and electrical consumption for cooling through dynamic simulation, two test models were developed in DesignBuilder software. For the green roof parameters, the values in a study in Singapore [6] were used as a reference due to having similar weather conditions.

\subsection{Description of the test model}

The two test models consisted of a one-story $80 \mathrm{~m}^{2}$ residential building (Figure 1(a)) and a two-story $200 \mathrm{~m}^{2}$ residential building $\left(100 \mathrm{~m}^{2}\right.$ each story), both with a $30 \%$ window-to-wall ratio (WWR) and a $3 \mathrm{~m}$ height per story (Figure 1(b)).

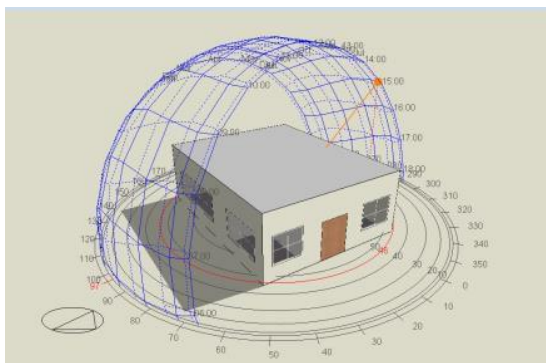

(a)

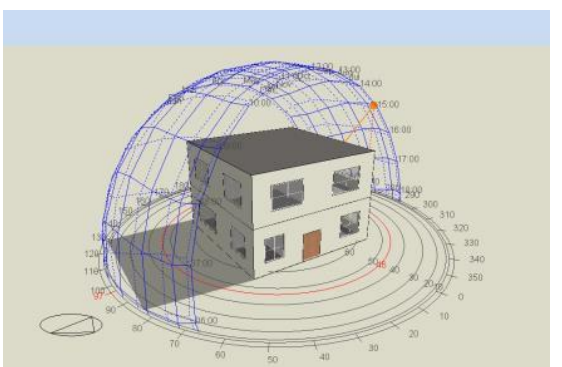

(b)

Fig. 1. Test models under study: (a) $80 \mathrm{~m}^{2}$ and (b) $200 \mathrm{~m}^{2}$.

Common construction materials for buildings in Panama were implemented. Both test models include generic clear $3 \mathrm{~mm}$ windows, a two-layer floor of granite and concrete, a four-layer roof (plasterboard, air, fiberglass and concrete), and three layer-external walls (mortar, concrete, mortar). The transmittance values (U) are presented in Table 1.

Table 1. $U$ values and thickness of the envelope elements of both buildings.

\begin{tabular}{|l|c|c|}
\hline Envelope elements & U-values $\left(\mathrm{W} / \mathrm{m}^{2}-\mathrm{K}\right)$ & Thickness $(\mathrm{m})$ \\
\hline External walls & 3.859 & 0.2100 \\
\hline Internal partitions & 0.364 & 0.2100 \\
\hline Windows & 6.121 & 0.0030 \\
\hline Roof (original roof OR) & 0.250 & 0.3375 \\
\hline Ground floor & 0.614 & 0.1150 \\
\hline Internal floor & 0.240 & 0.7600 \\
\hline
\end{tabular}


The dynamic simulations were carried out in two different operation modes: Passive and active. The passive mode implements a 24-hour natural ventilation schedule with an irrigation system, and the active mode implements an air conditioning usage schedule from 8:00 to 20:00 (same as the occupancy for both modes) with natural ventilation from 20:00 to 8:00 and a constant irrigation system (default settings for the irrigation system were used: 24-hour operation).

\subsection{Parametric analysis of the implementation of green roof}

The parametric analysis carried out consists of two parts. The first part focuses only on the parameters of the green roof vegetation layer. The second part aims to compare the green roof performance in reducing the cooling needs against non-green roofs.

\subsubsection{Parameters of the vegetation layer}

To carried out this first part, the values of the green roof parameters employed in [6] were used as a reference due to having similar weather conditions (Table 2). The same green roof properties were applied on both test models. The dynamic simulations were performed for both passive and active modes for the hottest months: March, April, and May. Then, the parametric analysis consisted of varying the values of each green roof parameter as shown in the two last columns in Table 2. Note here that Designbuilder was also used in [6], and the test values for some parameters were restricted by the software.

Table 2. Values implemented for green roof parameters.

\begin{tabular}{|l|c|c|c|}
\hline Parameters & Values from [6] & Test values & Increment \\
\hline Thermal absorptance (-) & 0.9 & $0.85,0.9,1$ & - \\
\hline Solar absorptance (-) & 0.7 & $0.6-0.9$ & 0.1 \\
\hline Visible absorptance (-) & 0.75 & $0.6,0.75,0.8,0.9$ & - \\
\hline Vegetation height (m) & 0.2 & $0.1,0.2-1$ & 0.2 \\
\hline Leaf Area Index (LAI) (-) & 2 & $0.5-3$ & 0.5 \\
\hline Leaf reflectivity (-) & 0.22 & $0.1,0.22,0.3,0.4$ & - \\
\hline Leaf emissivity (-) & 0.95 & $0.8,0.95,1$ & - \\
\hline Minimum stomatal resistance (s/m) & 180 & $\begin{array}{c}50-150,180, \\
200-300\end{array}$ & 50 \\
\hline $\begin{array}{l}\text { Maximum volumetric content of } \\
\text { moisture at saturation }\end{array}$ & 0.3 & $0.2-0.5$ & 0.1 \\
\hline $\begin{array}{l}\text { Minimum volumetric content of residual } \\
\text { moisture }\end{array}$ & 0.01 & $0.01-0.04$ & 0.01 \\
\hline Initial volumetric moisture content & 0.1 & $0.1,0.2,0.5$ & - \\
\hline
\end{tabular}

To evaluate the influence of each parameter changing, the monthly average values of four internal variables were chosen as indicators: Indoor temperature, Indoor relative humidity, roof heat gains, and total latent load. Finally, after performing several simulations, the most important parameters of the vegetation layer were highlighted for each test model under each operation mode.

\subsubsection{Evaluation of energy efficiency}

Once the most relevant parameters of the vegetation layer are identified, this second part analyses generic vegetation suitable for the local climate in terms of such relevant parameters. Here, four species were selected: Tradescantia spathacea Sw., Aloe Vera, Arachis hypogaea, and Sansevieria sp. Therefore, four green roofs (GR) were developed 
for each species, named GR1, GR2, GR3, and GR4, respectively. Besides, two additional GR were implemented: GR1* and GR2 ${ }^{* *}$, corresponding to GR1 and GR2 but with a different plant height of $0.4 \mathrm{~m}$ and $0.6 \mathrm{~m}$, respectively.

The dynamic simulations were performed for both test models only on active mode to compare the green roof performance against non-green roofs in minimizing the cooling needs, for the hottest month: March. Eight non-green roofs (R1 - R8) were included in the analysis, containing different insulation and thermal mass degrees. Other envelope elements were also varied in the analysis, such as building orientation, glazing type, WWR, and external walls.

\section{Results analysis and discussion}

\subsection{Sensitivity of building thermal performance to green roof parameters}

Regarding the vegetation layer parameters, figures 2 and 3 presents some of the results for the variation in the roof heat gains during a passive mode operation (lines) for each test model $80 \mathrm{~m}^{2}$ and $200 \mathrm{~m}^{2}$, respectively. The variation of such heat gains (in \%) with respect to the original green roof values (second column in Table 2) is also presented (bars).

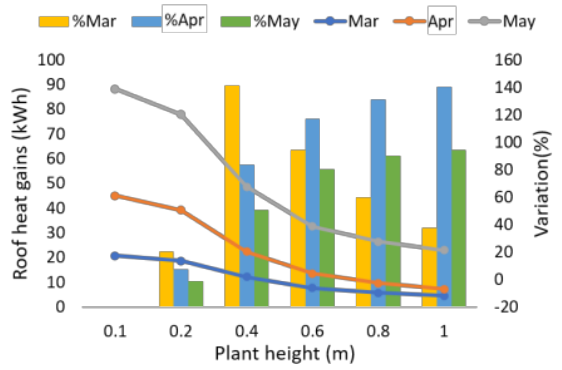

(a)

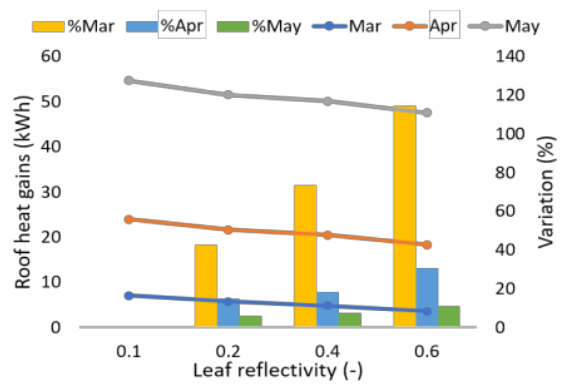

(c)

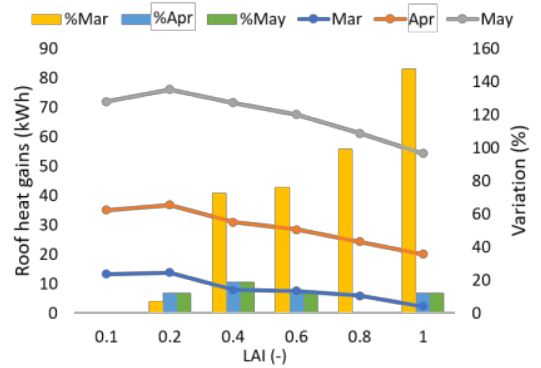

(b)

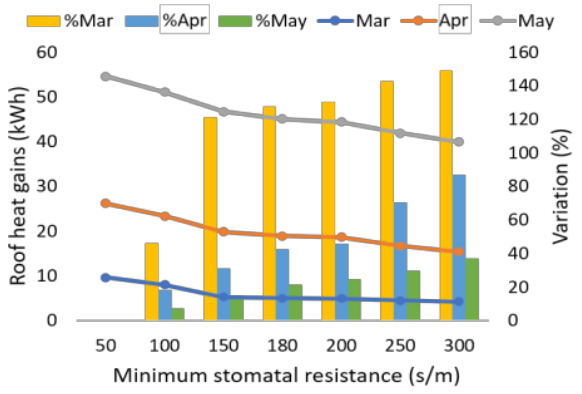

(d)

Fig. 2. Roof heat gains results in the $80 \mathrm{~m}^{2}$ model according to: (a) Plant height (b) LAI, (c) leaf reflectivity, and (d) minimum stomatal resistance.

For the case of the $80 \mathrm{~m}^{2}$ test model, it can be observed how the increase in the plant height reduces significantly (higher than $10 \%$ variation) the roof heat gains for all months, but only for height larger than $0.4 \mathrm{~m}$ (Figure 2(a)). The same can be observed for the stomatal resistance (Figure 2(d)). Conversely, for the LAI (Figure 2(b)) and leaf reflectivity (Figure 2(c)), the roof heat gains appear only to be significantly reduced for March.

On the other hand, the $200 \mathrm{~m}^{2}$ test model presents negative heat gains indicating that the green roof already contributes to cooling down the indoor environment (contrary to the 
$80 \mathrm{~m}^{2}$ test model). However, similar behavior can be observed for the plant height in Figure $3(\mathrm{a})$ ); the plant height should reach values higher than $0.4 \mathrm{~m}$ to minimize the heat gains. Moreover, no significant effect is encountered for the LAI (Figure 3(b)), leaf reflectivity (Figure 3(c)), and stomatal resistance (Figure 3(d)).

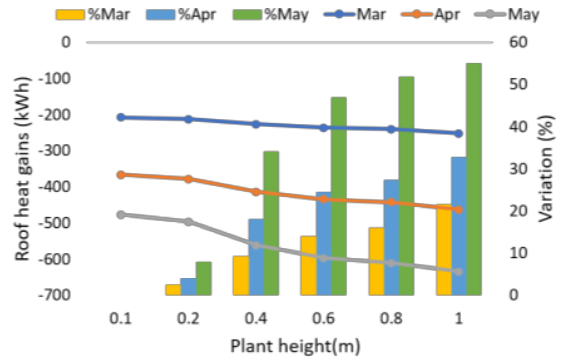

(a)

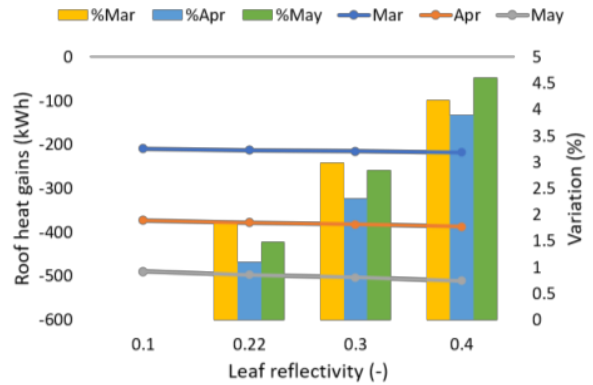

(c)

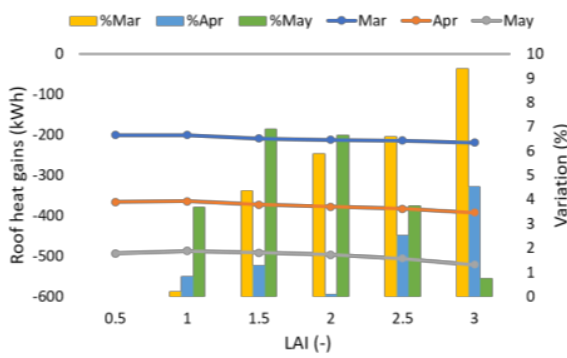

(b)

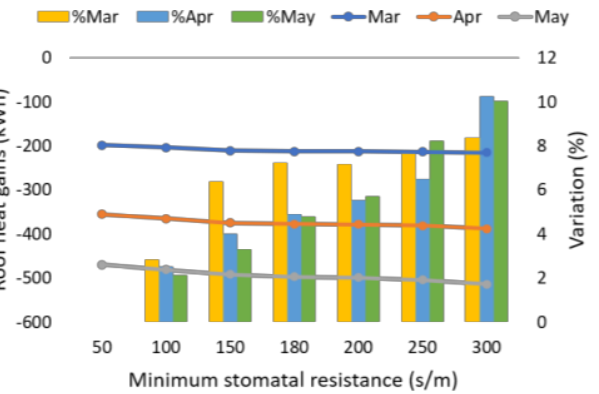

(d)

Fig. 3. Roof heat gains results in the $200 \mathrm{~m}^{2}$ model according to: (a) Plant height (b) LAI, (c) leaf reflectivity, and (d) minimum stomatal resistance.

The same analysis was performed for both test models during an active operation mode. The resulting important parameters are presented in Table 3, where the boxes marked with an " $x$ " indicate that significant changes were obtained in the overall decrease of the indoor temperature and roof heat gains in both operation modes for each test model.

Tabla 3. Resulting significant green roof parameters for each test model under each operation mode.

\begin{tabular}{|l|c|c|c|c|}
\hline Vegetation layer parameters & \multicolumn{2}{|c|}{ Passive mode } & \multicolumn{2}{c|}{ Active mode } \\
\hline Test model & $80 \mathrm{~m}^{2}$ & $200 \mathrm{~m}^{2}$ & $80 \mathrm{~m}^{2}$ & $200 \mathrm{~m}^{2}$ \\
\hline Plant height & $\mathrm{x}$ & $\mathrm{x}$ & $\mathrm{x}$ & $\mathrm{x}$ \\
\hline Leaf Area Index (LAI) & $\mathrm{x}$ & & $\mathrm{x}$ & $\mathrm{x}$ \\
\hline Leaf reflectivity & $\mathrm{x}$ & & $\mathrm{x}$ & \\
\hline Leaf emissivity & & & $\mathrm{x}$ & \\
\hline Minimum stomatal resistance & $\mathrm{x}$ & & $\mathrm{x}$ & \\
\hline
\end{tabular}

\subsection{Energy performance of green roof for cooling needs}

After identifying the most relevant parameters of the vegetation layer (Table 3), the four species considered in this study are presented in Table 4. Note here that the previous analysis in section 3.1 helped reduce the variables of the plant to be characterized or known, as this may require specialized laboratory tests. The values for the vegetation layer parameters presented in Table 4 were found in the literature. 
Table 4. Values of plants suitable for the Panamanian climate according.

\begin{tabular}{|c|c|c|c|c|}
\hline Parameters & GR1[7] & GR2 [8] & GR3 & GR4 \\
\hline \multicolumn{5}{|l|}{ Image } \\
\hline Plant height (m) & 0.3 & $\overline{0.3}$ & 0.1 & 0.6 \\
\hline Leaf Area Index (LAI) & 3.5 & 3.5 & 4.5 & 3.5 \\
\hline Leaf reflectivity (-) & 0.4 & 0.4 & 0.15 & 0.25 \\
\hline $\begin{array}{l}\text { Minimum stomatal } \\
\text { resistance }(\mathrm{s} / \mathrm{m})\end{array}$ & 230 & 230 & 180 & 200 \\
\hline $\begin{array}{l}\text { U-value }\left(\mathrm{W} / \mathrm{m}^{2}-\mathrm{K}\right) \\
\text { when in } \mathrm{GR}\end{array}$ & 0.3747 & 0.37470 & 0.3747 & 0.3747 \\
\hline
\end{tabular}

By implementing the four green roofs in Table 4, the parametric analysis performed for March for both test models under the active mode showed that for the $200 \mathrm{~m}^{2}$ model, the green roofs always present the lowest values regarding roof heat gains (Figure 4(a)) and cooling needs (Figure (b)). On the contrary, no significant roof heat gains and cooling need reduction was encountered whether implementing green or non-green roofs for the $80 \mathrm{~m}^{2}$ model.

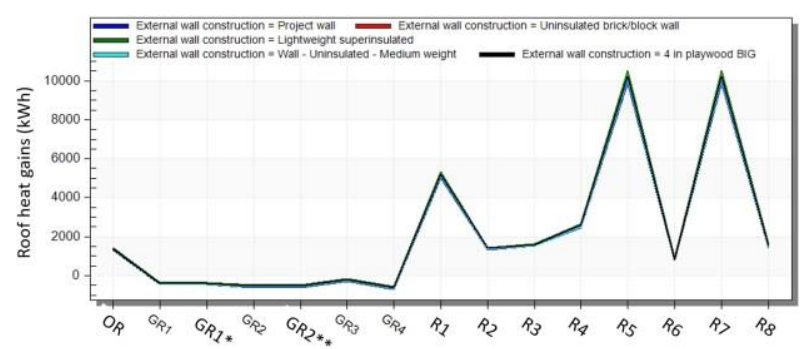

(a)

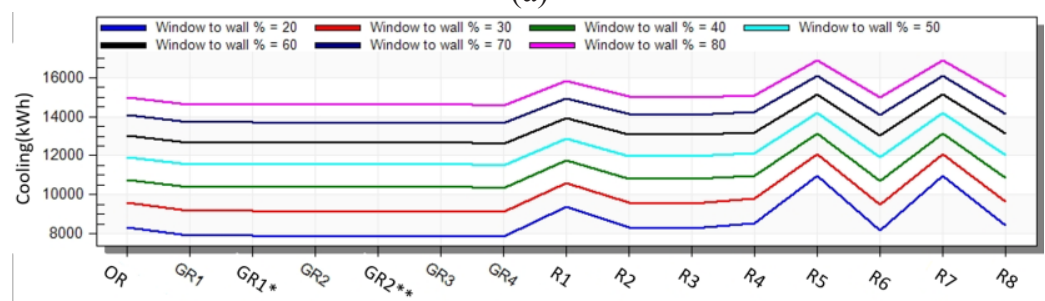

(b)

Fig. 4. Results in the $200 \mathrm{~m}^{2}$ test model for all roof tested: (a) Roof heat gains variation with different external wall types, and (b) electrical consumption variation for cooling with different window-towall ratio values.

\section{Conclusion}

The present research has evaluated the implementation of generic vegetation on the roof of buildings in Panama, in terms of electricity consumption for cooling, through dynamic simulation. Four plants suitable for the climate of Panama and resistant to solar radiation, high temperatures, and humidity were chosen: Tradescantia spathacea $S w$., Sansevieria sp., Aloe Vera, and Arachis hypogaea. Employing passive and mechanical mode in the 
simulations with 24-hour irrigation systems, it was possible to observe how the roof heat gains vary depending on the values given to the vegetation layer parameters. This led us to determine the most important parameters of the vegetation layer: plant height, leaf area index (LAI), leaf reflectivity, and stomatal resistance.

\section{Acknowledgements}

This study was supported by the Panamanian Institution Secretaría Nacional de Ciencia, Tecnología e Innovación (SENACYT) https://www.senacyt.gob.pa/, under the project code FID18-056, as well as supported by the Sistema Nacional de Investigación (SNI). The authors are grateful to the Faculty of Mechanical Engineering of the Technological University of Panama for their collaboration.

\section{References}

1. S. A. ETESA, Empresa de transmisión eléctrica, p. 240, 2019, Accessed: Sep. 02, 2019. [Online]. Available: https://www.etesa.com.pa/documentos/tomo_i estudios_bsicos_2018_2032-1281080089.pdf.

2. C. R. Braithwaite, "The Case for Green Roofs Exploring green roof policy as a tool to increase urban sustainability . A Case Study of Port of Spain , Trinidad \& Tobago," no. September, 2012.

3. GSA (General Services Administration), no. May, p. 152, 2011, [Online]. Available: http://www.gsa.gov/portal/mediaId/158783/fileName/The_Benefits_and_Challenges_o f_Green_Roofs_on_Public_and_Commercial_Buildings.action.

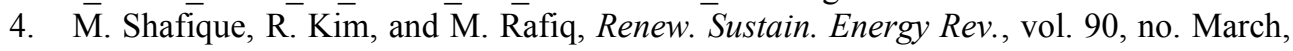
pp. 757-773, 2018, doi: 10.1016/j.rser.2018.04.006.

5. J. B. D. H.F. Castletona, V. Stovinb, S.B.M. Beckc, p. 10, 2010.

6. W. Nyuk Hien, T. Puay Yok, and C. Yu, Build. Environ., vol. 42, no. 1, pp. 25-54, 2007, doi: 10.1016/j.buildenv.2005.07.030.

7. Universidad de Panamá, "Herbario - Universidad de Panamá." http://herbario.up.ac.pa/Herbario/ (accessed Sep. 22, 2019).

8. A. E. LatAm Prime, "Asesores Panameños de Tierras, S.A.," Accessed: Sep. 22, 2019. [Online]. Available: https://www.asesorespanamenostierras.com/es/blog-es. 